\title{
An Evaluation of the Pearsonian Type I Curve of Fertility for Aboriginal Populations in Canada, 1996 to 2001
}

\author{
Ravi B.P. Verma \\ Statistics Canada \\ ravi.verma@statcan.ca \\ Shirley Loh \\ Statistics Canada \\ lohsy@planet.eon.net
}

\begin{abstract}
In 2005, Statistics Canada published new projections of the Aboriginal populations (North American Indians, Métis, and Inuit) in Canada, the provinces and territories from 2001 to 2017. To derive the number of births in these projections, the age-specific fertility rates were simulated by fitting the Pearsonian Type I curve using the projected fertility parameters: total fertility rates, mean ages of fertility, and modal ages of fertility. For the base period 1996 to 2001, the parameters were estimated from the age-specific fertility rates derived from the 2001 Census, using the "own-children method." This paper evaluates the goodness of fit between the age-specific fertility rates developed by the Type I curve and the estimated age-specific fertility rates for Aboriginal identity groups for the period 1996 to 2001 for Canada and for high and low fertility regions. Tests of validity of the Type I curve indicate that this method is appropriate for estimating/projecting the number of births for the Aboriginal populations.
\end{abstract}

Key Words: Aboriginal populations, North American Indians, Métis, Inuit, own-children method, Pearsonian type I curve

\section{Résumé}

En 2005, Statistique Canada publiait de nouvelles projections des populations autochtones (Indiens de l'Amérique du Nord, Métis et Inuit) au Canada, les provinces et les territoires de 2001 à 2017. Afin de calculer le nombre de naissances dans ces projections, les taux de fécondité par âge ont été simulés en ajustant la courbe de Type I de Pearson selon les paramètres de fécondité projetés: l'indice synthétique de fécondité, l'âge moyen à l'accouchement et l'âge modal à l'accouchement. Pour la période de base de 1996 à 2001, ces paramètres ont été estimés selon les taux de fécondité par âge générés par la méthode du «décompte des enfants au foyer » avec les données des enfants âgés de 0 à 4 ans et les femmes dans le groupe d'âge de 15 à 49 ans provenant du Recensement du Canada de 2001. Cet article évalue la qualité de l'ajustement entre le taux de fécondité par âge développé selon la courbe de Type I et le taux de fécondité par âge estimé des groupes d'identité autochtone pour la période 1996 à 2001 
au Canada dans les régions de forte et de basse fécondité. Les tests de validité de la courbe de Type I indiquent que cette méthode est appropriée à l'estimation/projection du nombre de naissances des populations autochtones.

Mots clés: populations autochtones, Indiens de l'Amérique du Nord, Métis, Inuit, méthode du décompte des enfants au foyer, courbe de Type I de Pearson

\section{Introduction}

In 2005, Statistics Canada published new projections of the Aboriginal populations (North American Indians, Métis, and Inuit) in Canada, the provinces and territories: 2001-2017 (see Statistics Canada, 2005). These projections were also produced by type of residence: on reserves, Census Metropolitan Areas (CMAs), urban non-Census Metropolitan Areas (NCMAs), and rural areas. Taking into account net undercoverage it was estimated that in 2001 in Canada, 1,066,500 people identified themselves as Aboriginal. According to selected scenarios based on demographic factors (births, deaths, and net migration), by 2017 this number could increase to between 1,390,200 and 1,431,800. Compared with the total Canadian population, under the medium growth scenario the Aboriginal population is likely to continue its faster growth, $1.8 \%$ vs. $0.7 \%$ per annum. The North American Indian group was projected to increase from 713,100 in 2001 to 971,200 in 2017 (1.9\% per annum); the Métis from 305,800 in 2001 to 380,500 (1.4\% per annum); and the Inuit population, projected to grow the fastest, reaching 68,400 in 2017 from 47,600 in 2001 (2.3\% per annum).

The higher growth of the Aboriginal population compared with the Canadian population was largely due to its higher fertility. ${ }^{1}$ The number of births in these projections was based on the age-specific fertility rates simulated by fitting the Pearsonian Type I curve with three parameters: total fertility rates, mean ages of fertility, and modal ages of fertility. In the absence of vital statistics for the three Aboriginal identity groups in Canada, these parameters were projected based on the estimated age-specific fertility rates by five-year age groups generated by the "own-children method" from the 2001 Census of Canada (Statistics Canada, 2005).

For the purpose of developing projections of population for registered Indians,

1. The projections of Aboriginal population published in 2005 by Statistics Canada were based on the cohort-component method which took into consideration selected assumptions on demographic factors of fertility, mortality, and internal migration. In addition, a special scenario was generated to provide further insights into the future growth of the Aboriginal population if a nondemographic factor, the transfer of identity from mother to children, was also considered. Previous studies show that aside from their higher fertility, the contribution of a nondemographic factor, namely ethnic mobility, to the large growth of the Aboriginal groups was observed between 1986 and 1996 (Guimond, 1999) and 1996 and 2001 (Verma, 2005). Ethnic mobility refers to people changing the reporting of their Aboriginal affiliation from one census to the next (Siggner and Hagey, 2004). The special scenario shows that if the transferability of Aboriginality from mother to children from 2001 continues into the future, its contribution to the overall growth of the Métis will be the largest of the Aboriginal groups from 2001 to $2017,16 \%$, smaller for the North American Indians, $8 \%$ and least for the Inuit, $3 \%$. 
Statistics Canada has also estimated total fertility rates from the years 1974 to 2002 using the Indian Registry database for Canada and nine regions, Atlantic, Quebec, Ontario, Manitoba, Saskatchewan, Alberta, British Columbia, Yukon and Northwest Territories (Loh, 1997; Statistics Canada, 2002). The total fertility rates were calculated based on the adjusted number of births and women due to underreporting and late-reporting of vital events which were limited to the Indian Registry database. It was estimated that the TFRs of Registered Indians experienced a decline of 1.56 children per woman from 4.42 in 1974 to 2.86 in 2001. Since the Indian Registry does not provide information on births for the three groups of the Aboriginal population, we calculated the TFRs based on census data. However, the TFRs for the registered Indians estimated from the Indian Register were used in evaluating the estimated TFRs using the own-children method from the census for the North American Indian population.

Ram (2004) made a comparison between fertility rates from the Indian Registry and those from the census using the own-children method for the period 1991-96. The total fertility rate for the 1991-96 period from the census was 2.86 while that from the Indian registry was 2.81 , showing a very similar level of fertility for the registered Indians estimated from the two sets of data sources.

If the mean age of fertility is larger than the modal age, the distribution of agespecific fertility rates can be reasonably well approximated by using the Pearsonian Type I curve (Verma and Loh, 1992; Verma et al., 1996; Statistics Canada, 1975). This curve was used in Canada until the release of the population projections for Canada, the provinces and territories, 1993-2016 (Statistics Canada, 1994). For this and subsequent publications on population projections (Statistics Canada, 1994; 2001) the Pearsonian Type III curve was used to graduate the age-specific fertility rates, as the mean ages and modal ages of fertility were approaching similar values for the Canadian population. However, for the Aboriginal identity groups, it was estimated that the mean ages of fertility in 2001 for the North American Indians, Métis, and Inuit women were $26.29,26.31$, and 28.40 years, respectively - considerably higher than their respective modal ages of 21.90, 22.93, and 23.53 years. Therefore, we decided to graduate age-specific fertility rates based on the Type I curve to project the number of births. The goodness of fit of the Type I curve for estimating the age-specific fertility rates and the number of births for the Aboriginal populations using the census data was not examined. Thus, two questions are explored in this paper. How well does the Type I curve fit the estimated age-specific fertility rates? What will be the level of closeness of fit between the derived number of births from the Type I curve and the estimated number of births using the "own-children method"? The findings of this research will be useful to assess the quality of the projected Aboriginal population, particularly the projected number of births.

In the following sections, we provide the data sources and methods, results and concluding remarks. 


\section{Sources of Data and Methodology}

In Canada, the birth registration statistics are the most comprehensive data source on births. Unfortunately, this data set does not provide information on fertility by Aboriginal identity. In fact, direct data on the fertility of the Aboriginal peoples are not available. Indian and Northern Affairs Canada (INAC) compiles data on the First Nations (registered Indian) population through the Indian Registry, but there is no administrative source specific to the nonstatus Indian, Métis, or Inuit populations. To maintain internal consistency for all three Aboriginal groups, birth data from the Indian Registry system were not used in this paper. Instead, we used the 2001 Census data and an indirect technique, known as the "own-children method," to derive the fertility levels of the three Aboriginal groups (Grabill and Cho, 1965; Cho, Grabill, and Bogue, 1970; Cho, 1971; 1973; Ram, 1991; 2003; 2004; Ram and Romaniuc, 1985). Appendix 1 presents the details of the own-children method. Also, we calculated the mean and modal ages of fertility required by the Pearsonian Type I curve of fertility in the projection model of Statistics Canada. These parameters were calculated for Canada, a high-fertility region, and a low-fertility region. For the North American Indian and the Métis populations, the high-fertility region comprised Manitoba, Saskatchewan, the Yukon Territory, the Northwest Territories, and Nunavut, while the low-fertility region comprised Newfoundland and Labrador, Prince Edward Island, Nova Scotia, New Brunswick, Quebec, Ontario, Alberta, and British Columbia. Inuit fertility parameters were based on Newfoundland and Labrador, Quebec, and Nunavut.

\section{Pearson's System of Frequency Curves}

An effective approach to select a particular Type of Pearson's curve is to examine the $x, \beta_{1}$ and $\beta_{2}$ criteria and then estimate the parameters of that distribution by Maximum Likelihood (Stuart and Ord, 1987, Elderton, 1930, Verma and Ford, 1992, Verma and Loh, 1992).

$$
\beta_{1}=\frac{\mu_{3}^{2}}{\mu_{2}{ }^{3}} \quad \beta_{2}=\frac{\mu_{4}}{\mu_{2}{ }^{2}}
$$

The Kappa $(\kappa)$ criterion is given by:

$$
\frac{\beta_{1}\left(\beta_{2}+3\right)^{2}}{4\left(2 \beta_{2}-3 \beta_{1}-6\right)\left(4 \beta_{2}-3 \beta_{1}\right)}
$$


where $\mu_{2}, \mu_{3}$, and $\mu_{4}$ are the second, third, and fourth moments about the mean. The $\kappa$ criterion measures the extent of deviation from the symmetrical curve. A negative value of $\kappa$ indicates that the curve in question is negatively asymmetrical while a positive value of $\kappa$ indicates that the curve is positively asymmetrical. The $\kappa$ criterion may have any value from $-\infty$ to $+\infty$, and the different Types of Pearsonian curves cover all these possible values without overlap.

We have computed $\kappa$ values from age-specific fertility rates for the three Aboriginal groups for the period 1996 to 2001 at the Canada level and for its two fertility regions: high level and low level (see Table 1). For each area, the $\kappa$ values are negative for each group and the total Aboriginal population. This implies that the pattern of age-specific fertility rates for each of the three Aboriginal groups and the total Aboriginal group is asymmetrical.

The decision process to select a Pearson curve using the $\kappa$ value is not always reliable. The value of $\kappa$ is found to be abnormal when the value of $2 \beta_{2}-2 \beta_{1}-6$ is close to zero (Mitra, 1992). In view of this, Verma and Ford (1992) explored the values of $\beta_{1}$ and $\beta_{2}$ to determine the appropriate curve which would best fit the fertility data.

\section{Table 1. Fertility Rates per 1,000 Women (by Own-Children Method) by Age Group and Summary Measures (TFR, Mean Age, Modal Age, B1, B2 and K Values) for Aboriginal Identity Groups in Two Fertility Regions in Canada, 1996-2001}

\begin{tabular}{|c|c|c|c|c|c|c|c|c|}
\hline \multirow[b]{2}{*}{$\begin{array}{c}\text { Age } \\
\text { group }\end{array}$} & \multicolumn{4}{|c|}{ Total Canada } & \multicolumn{2}{|c|}{$\begin{array}{c}\text { High Fertility } \\
\text { Regions (1) }\end{array}$} & \multicolumn{2}{|c|}{$\begin{array}{c}\text { Low Fertility } \\
\text { Regions (2) }\end{array}$} \\
\hline & $\begin{array}{c}\text { Total } \\
\text { Aboriginal } \\
\text { Population }\end{array}$ & $\begin{array}{c}\text { North } \\
\text { American } \\
\text { Indian }\end{array}$ & Métis & $\begin{array}{c}\text { Inuit } \\
\text { (3) }\end{array}$ & \begin{tabular}{|c} 
North \\
American \\
Indian \\
\end{tabular} & Métis & \begin{tabular}{|c} 
North \\
American \\
Indian
\end{tabular} & Métis \\
\hline $15-19$ & 82.9 & 94.1 & 59.2 & 82.6 & 120.7 & 66.8 & 81.6 & 55.1 \\
\hline $20-24$ & 169.6 & 182.1 & 140.7 & 178.5 & 230.5 & 155.4 & 159.8 & 132.3 \\
\hline $25-29$ & 141.6 & 145.6 & 126.4 & 165.6 & 170.9 & 141.5 & 134.7 & 118.1 \\
\hline $30-34$ & 85.2 & 89.0 & 71.0 & 113.7 & 96.4 & 80.0 & 86.4 & 67.0 \\
\hline $35-39$ & 38.3 & 41.5 & 28.3 & 65.1 & 53.3 & 35.4 & 37.2 & 24.5 \\
\hline $40-44$ & 14.3 & 16.4 & 6.7 & 49.4 & 25.9 & 5.9 & 13.3 & 6.9 \\
\hline $45-49$ & 3.0 & 2.7 & 2.0 & 18.3 & 3.7 & 0.9 & 2.5 & 2.4 \\
\hline TFR (4) & 2.7 & 2.9 & 2.2 & 3.4 & 3.5 & 2.4 & 2.6 & 2.0 \\
\hline Mean age & 26.4 & 26.3 & 26.3 & 28.4 & 26.2 & 26.3 & 26.4 & 26.3 \\
\hline Modal age & 23.8 & 21.9 & 22.9 & 23.5 & 21.0 & 23.1 & 22.5 & 22.9 \\
\hline B1 value & 0.4 & 0.4 & 0.3 & 0.3 & 0.5 & 0.2 & 0.3 & 0.3 \\
\hline B2 value & 2.9 & 2.9 & 3.0 & 2.4 & 2.9 & 2.7 & 2.8 & 3.1 \\
\hline $\mathrm{K}$ - value & -0.2 & -0.2 & -0.3 & -0.1 & -0.2 & -0.1 & -0.2 & -0.3 \\
\hline
\end{tabular}

(1) High Fertility Region: Manitoba, Saskatchewan, Yukon Territory, Northwest Territories and Nunavut

(2) Low Fertility Region: Newfoundland and Labrador, Prince Edward Island, Nova Scotia, New Brunswick, Quebec, Ontario, Alberta, and British Columbia

(3) TFR for Inuit is based on Newfoundland and Labrador, Quebec and Nunavut.

(4) Total fertility rate (TFR) is expressed as births per woman. 


\section{$\beta_{1}$ and $\beta_{2}$ coefficients}

Stuart and Ord (1987) have also devised a $\beta_{1}$ and $\beta_{2}$ chart for the Pearson system. From the chart, it appears that the Type I curve should be accepted under the following limits of $\beta_{1}$ and $\beta_{2}$ : for Type I, $\beta_{1}>0,2<\beta_{2}<3$. At the Canada level and for its two fertility regions, analyses of the $\beta_{1}$ coefficients showed that they were all positive for each Aboriginal identity group (see Table 1 ). The $\beta_{1}$ coefficients were very low.

In general, $\beta_{2}$ coefficients of the fertility distribution computed for each Aboriginal identity group were between 2 and 3 with the exception of Métis in the low fertility region, where $\beta_{2}$ equals 3.1 (see Table 1 ). However, considering the relationship between the mean and modal ages of fertility for Métis in the low fertility region, in Table 1 it can be seen that the mean age of fertility was much higher than the modal age, 26.3 vs 22.9 years. So, the Type I curve is also suitable for graduating fertility rates by age for Métis women.

In sum, the values of the above mentioned three parameters of fertility distribution support that, regardless of fertility region, the Type I curve is an appropriate curve for graduating age-specific fertility rates for each Aboriginal identity group in Canada and its two fertility regions.

\section{Method of Fitting Pearsonian Type I Curve}

The method of graduating the distribution of age-specific fertility rates from given values of total fertility rates, the mean and the modal ages are based on two assumptions. First, the distribution can be approximated by a Pearsonian Type I curve and second the fertility curve is bounded by ages 15 and 50 years.

The Type I curve can be expressed as:

$$
\begin{gathered}
Y=Y_{0}\left(1+\frac{x}{a_{1}}\right)^{m_{1}}\left(1-\frac{x}{a_{2}}\right)^{m_{2}} \\
a_{1} \leq x \leq a_{2}
\end{gathered}
$$

Where $\mathrm{x}$ is measured as the deviation from the mode, it follows that the specification of the mode immediately determines $\mathrm{a}_{1}$ and $\mathrm{a}_{2}$ due to the second assumption as

$$
\mathrm{a}_{1}=\text { mode }-15
$$

and

$$
\mathrm{a}_{2}=50-\text { mode }
$$

The origin at the mode also imposes restriction in the parameters, namely

$$
\frac{m_{1}}{a_{1}}=\frac{m_{2}}{a_{2}}
$$

The density function as shown in (1) will be used to produce graduated agespecific fertility rates for each Aboriginal group in Canada and the two fertility regions. The results are shown in Table 2. 


\section{Adjustment to Age-specific Fertility Rates Fitted by Pearson Type I Curve}

Total fertility rates of the age-specific fertility rates graduated by the Pearson Type I curve are slightly different from the total fertility rates used as inputs in the model. In order to achieve consistency in total fertility rates between the fitted values and

Table 2. Age-specific Fertility Rates (per 1,000 Women) Based on Pearson Type I Curve by Aboriginal Identity Group and Fertility Region, Canada, 19962001.

\begin{tabular}{|c|c|c|c|c|c|c|c|}
\hline \multirow[b]{2}{*}{ Age group } & \multicolumn{3}{|l|}{ Canada } & \multicolumn{2}{|c|}{$\begin{array}{l}\text { High fertility } \\
\text { region (1) }\end{array}$} & \multicolumn{2}{|c|}{$\begin{array}{l}\text { Low fertility } \\
\text { region (2) }\end{array}$} \\
\hline & $\begin{array}{l}\text { North } \\
\text { American } \\
\text { Indian }\end{array}$ & Métis & Inuit(3) & \begin{tabular}{|l} 
North \\
American \\
Indian
\end{tabular} & Métis & \begin{tabular}{|l} 
North \\
American \\
Indian
\end{tabular} & Métis \\
\hline \multicolumn{8}{|c|}{ ASFRs simulated by fitting the type I curve } \\
\hline $15-19$ & $\mid 112.2$ & 75.1 & 110.5 & 148.6 & 81.5 & 94.7 & 70.9 \\
\hline $20-24$ & 147.0 & 117.2 & 140.4 & 175.3 & 132.7 & 133.9 & 109.2 \\
\hline $25-29$ & 130.9 & 107.7 & 137.5 & 153.0 & 122.9 & 121.8 & 100.2 \\
\hline $30-34$ & 96.2 & 76.5 & 119.8 & 114.3 & 86.3 & 89.3 & 71.3 \\
\hline 35-39 & 57.5 & 41.6 & 92.6 & 71.7 & 45.7 & 52.1 & 39.1 \\
\hline $40-44$ & 24.4 & 14.8 & 59.1 & 33.5 & 15.5 & 21.1 & 14.1 \\
\hline $45-49$ & 4.3 & 1.9 & 21.8 & 7.1 & 1.8 & 3.4 & 1.8 \\
\hline $\operatorname{TFR}(3,4)$ & 2.9 & 2.2 & 3.4 & 3.5 & 2.4 & 2.6 & 2.0 \\
\hline \multicolumn{8}{|c|}{ Simulated ASFRs adjusted to have TFRs equal to those obtained by "own-children method" } \\
\hline $15-19$ & $\mid 112.0$ & 75.0 & 109.1 & $\mid 148.1$ & 81.4 & 94.5 & 70.8 \\
\hline $20-24$ & 146.7 & 117.1 & 138.6 & 174.8 & 132.6 & 133.7 & 109.1 \\
\hline $25-29$ & 130.7 & 107.6 & 135.8 & 152.6 & 122.8 & 121.6 & 100.1 \\
\hline $30-34$ & 96.0 & 76.4 & 118.3 & 114.0 & 86.2 & 89.1 & 71.3 \\
\hline $35-39$ & 57.3 & 41.5 & 91.5 & 71.5 & 45.6 & 52.0 & 39.1 \\
\hline $40-44$ & 24.4 & 14.8 & 58.3 & 33.4 & 15.5 & 21.0 & 14.1 \\
\hline $45-49$ & 4.3 & 1.9 & 21.5 & 7.1 & 1.8 & 3.4 & 1.8 \\
\hline TFR (4) & 2.9 & 2.2 & 3.4 & 3.5 & 2.4 & 2.6 & 2.0 \\
\hline Adjustment factor & 0.998 & 0.999 & 0.987 & 0.997 & 0.999 & 0.998 & 0.999 \\
\hline$x^{2}(5)$ & 0.002 & 0.002 & 0.000 & 0.000 & 0.005 & 0.016 & 0.002 \\
\hline
\end{tabular}

(1) High fertility region: Manitoba, Saskatchewan, Yukon Territory, Northwest Territories and Nunavut.

(2) Low fertility region: Newfoundland and Labrador, Prince Edward Island, Nova Scotia, New Brunswick, Quebec, Ontario, Alberta and British Columbia.

(3) TFR for Inuit is based on Newfoundland and Labrador, Quebec and Nunavut

(4) Total fertility rate (TFR) is expressed as births per woman.

(5) The Chi-square tests the differences in age-specific fertility rates by age group for each Aboriginal group according to the "own children method" and the adjusted type I curve. The level of significance of $x^{2}$ with 4 degrees of freedom is always much less than 0.05 level (9.49), hence the differences between the two methods are not statistically significant. 
the input values, adjustment factors were applied to the age-specific fertility rates fitted by the Pearson Type I curve (see Table 2). The adjustment factors were obtained by taking the ratio of total fertility rates according to the age-specific fertility rates derived by the "own-children method" to the total fertility rates fitted by the Pearson Type I curve. The adjusted age-specific fertility rates can be found in Table 2.

\section{Tests of Validity}

Table 3 compares the relative differences in the estimated number of births based on the "own-children method" to the number of births generated by the Type I model for the 1996 to 2001 period. The range of deviation between these two methods varies from $-0.11 \%$ for Inuit at the Canada level to $1.42 \%$ for Métis in the low fertility region.

Table 3. Total Number of Births, Own-children Method vs Pearson Type I Curve by Aboriginal Identity Group and Fertility Region, Canada, 1996-2001

\begin{tabular}{|c|c|c|c|c|c|c|c|}
\hline \multirow[b]{2}{*}{ Births } & \multicolumn{3}{|c|}{ Canada } & \multicolumn{2}{|c|}{$\begin{array}{l}\text { High fertility } \\
\text { region (1) }\end{array}$} & \multicolumn{2}{|c|}{$\begin{array}{c}\text { Low fertility region } \\
\text { (2) }\end{array}$} \\
\hline & $\begin{array}{l}\text { North } \\
\text { American } \\
\text { Indian }\end{array}$ & Métis & Inuit(3) & $\begin{array}{l}\text { North } \\
\text { American } \\
\text { Indian }\end{array}$ & Métis & $\begin{array}{l}\text { North } \\
\text { American } \\
\text { Indian }\end{array}$ & Métis \\
\hline Pearson type I curve & 71,956 & 26,585 & 6,108 & 27,589 & 10,952 & 44,597 & 15,720 \\
\hline $\begin{array}{l}\text { Own-children } \\
\text { method }\end{array}$ & 71,615 & 26,407 & 6,115 & 27,565 & 11,007 & 44,324 & 15,500 \\
\hline $\begin{array}{l}\text { Relative difference } \\
(\%)\end{array}$ & 0.48 & 0.68 & -0.11 & 0.09 & -0.50 & 0.62 & 1.42 \\
\hline
\end{tabular}

(1) High Fertility Region: Manitoba, Saskatchewan, Yukon Territory, Northwest Territories and Nunavut.

(2) Low Fertility Region: Newfoundland and Labrador, Prince Edward Island, Nova Scotia, New Brunswick, Quebec, Ontario, Alberta and British Columbia.

(3) Births for Inuit are based on data from Newfoundland and Labrador, Quebec and Nunavut.

\section{Results}

For the general Canadian population, a comparison of the annual number of births for the period 1926 to 1970 generated by the Pearsonian Type I curve and the actual number of births for the same period was performed by Romaniuc (1975). The tests showed that, on the whole, the values derived from the model almost coincided with the actual values, there were only a few deviations of $1 \%$, and deviations of $2 \%$ were rare. Verma and Loh (1992) have evaluated the application of the Pearsonian Type I curve to fertility by age of women for Canada, provinces and territories, 1980 to 1989. In the majority of cases, they found that the Pearsonian Type I curve fits well, the goodness of fit varied by reproductive age interval. Best results were seen in the age interval of 20-49. The values of $\kappa$ (kappa) were negative and less than -0.14 . In 
addition, mean ages were higher by $6 \%$ over the modal age. These findings for Canadian women are comparable to the findings presented in the current study for the Aboriginal identity group women.

Based on a thorough evaluation of the performance of Pearson curves Types I, II, III and normal distribution in representing the age-specific fertility rates for Canadian women from 1971 to 1989 , Verma and Ford (1992) found that the Type III curve better represented the fertility curve for Canada, provinces and territories, when the differences between the mean and modal ages of fertility had been narrowing and the shape of the distribution of child-bearing was becoming more symmetrical. However, the mean ages of fertility of the three Aboriginal groups remained continuously higher than the modal ages in the 1996-2001 period, which substantiates the suitability of using the Pearson Type I curve for generating the agespecific fertility rates for the Aboriginal women. Also, for each area, the $\kappa$ values are negative for each group and the total Aboriginal population and were less than -0.10 (See Table 1). For the Aboriginal identity groups, it was observed that the mean ages of fertility in 2001 for the North American Indians, Métis, and Inuit women were $26.29,26.31$, and 28.40 years, respectively - these were considerably higher than their respective modal ages of $21.90,22.93$, and 23.53 years. Thus, these criteria are strongly in favour of using the Pearson Type I curve for generating the age-specific fertility rates for the Aboriginal women.

Tests of goodness of fit between the two methods are analyzed in Charts 1 to 7 , based on age-specific fertility rates produced by the two methods (own-children method and the Pearson Type I curve) shown in Tables 1 and 2. It can be seen that the Type I based age-specific fertility rates are somewhat systematically different from

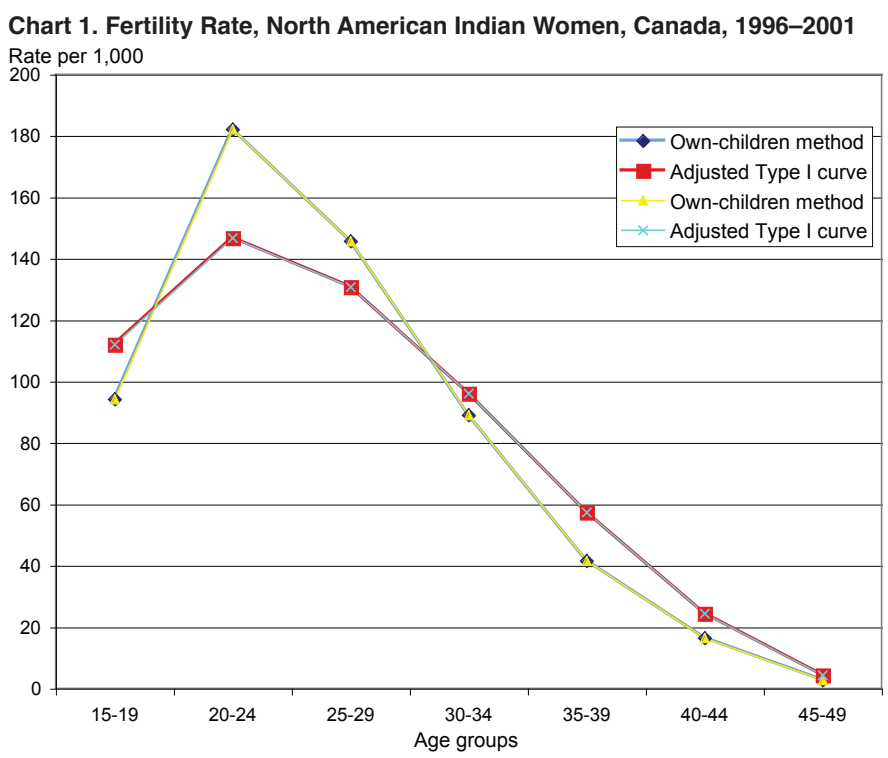


Chart 2. Fertility Rates, North American Indian Women, High-fertility region, Canada, 1996-2001

Rate per 1,000

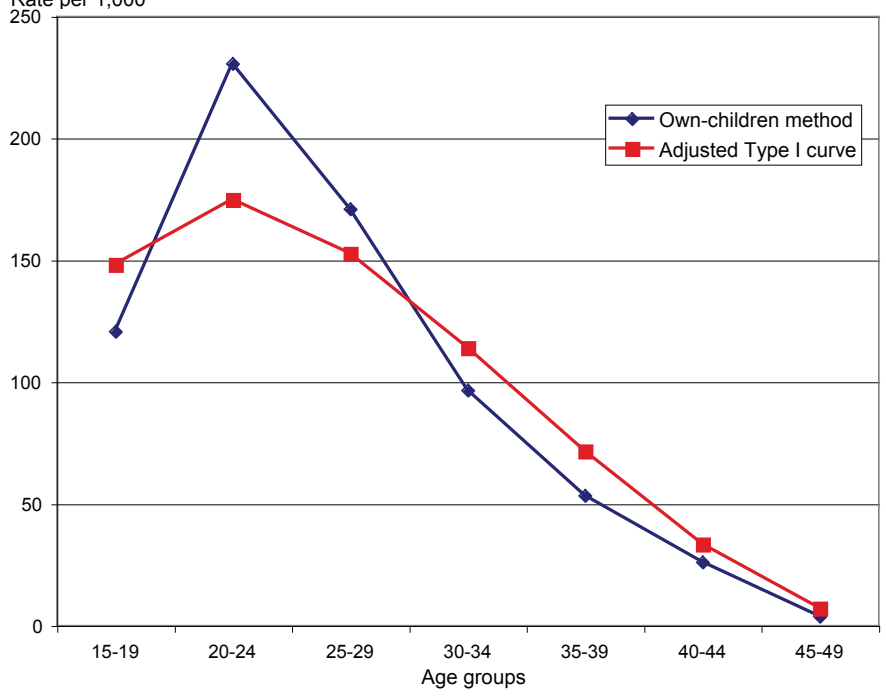

Chart 3. Fertility Rates, North American Indian Women, Low-fertility Region, Canada, 1996-2001

Rate per 1,000

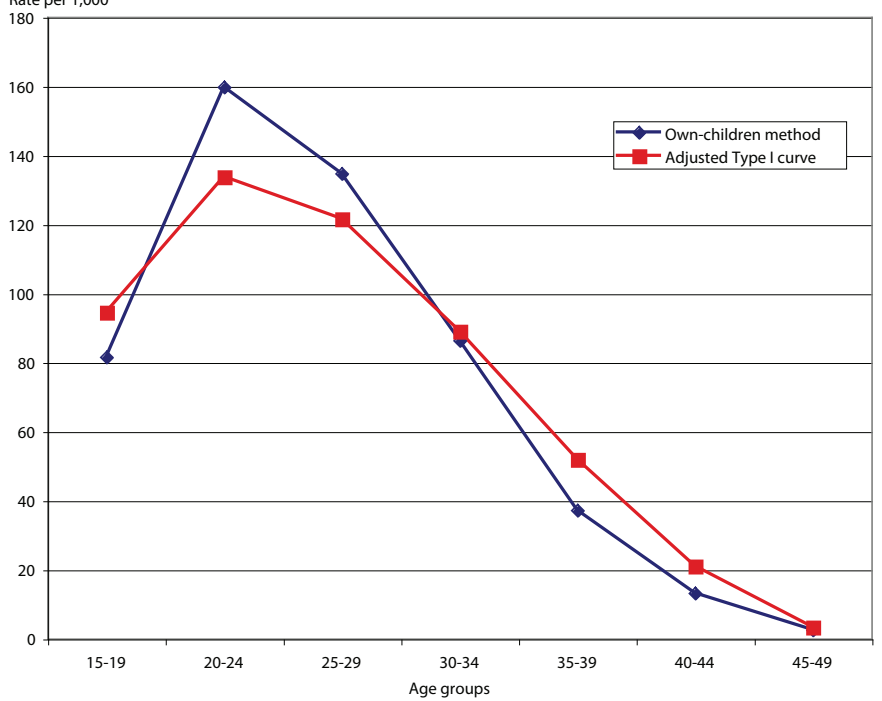


Chart 4. Fertility Rates, Metis Women, Canada, 1996-2001

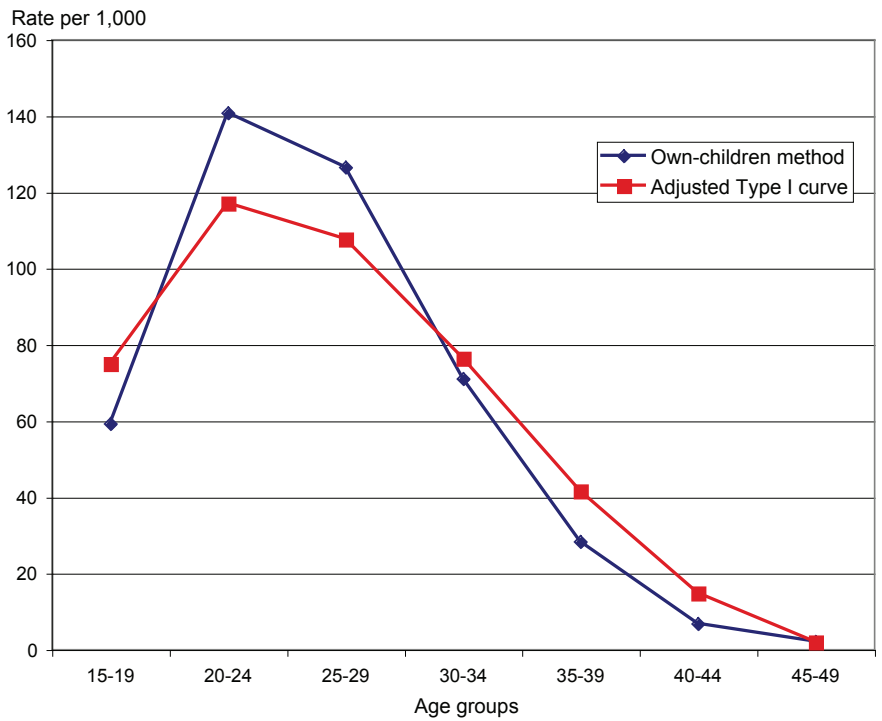

Chart 5. Fertility Rates, Metis Women, High-fertility Region, Canada,

1996-2001

Rate per 1,000

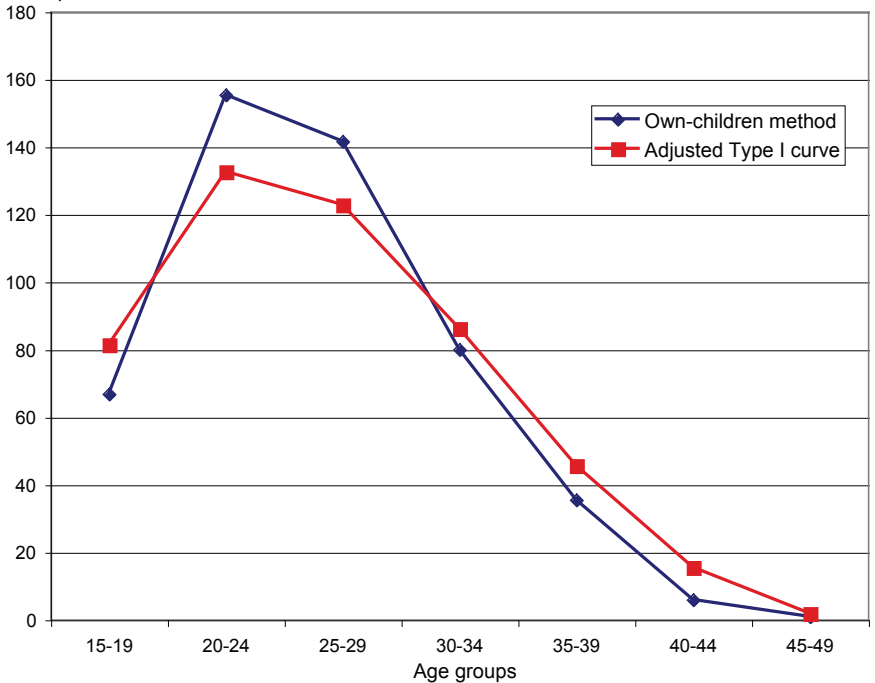




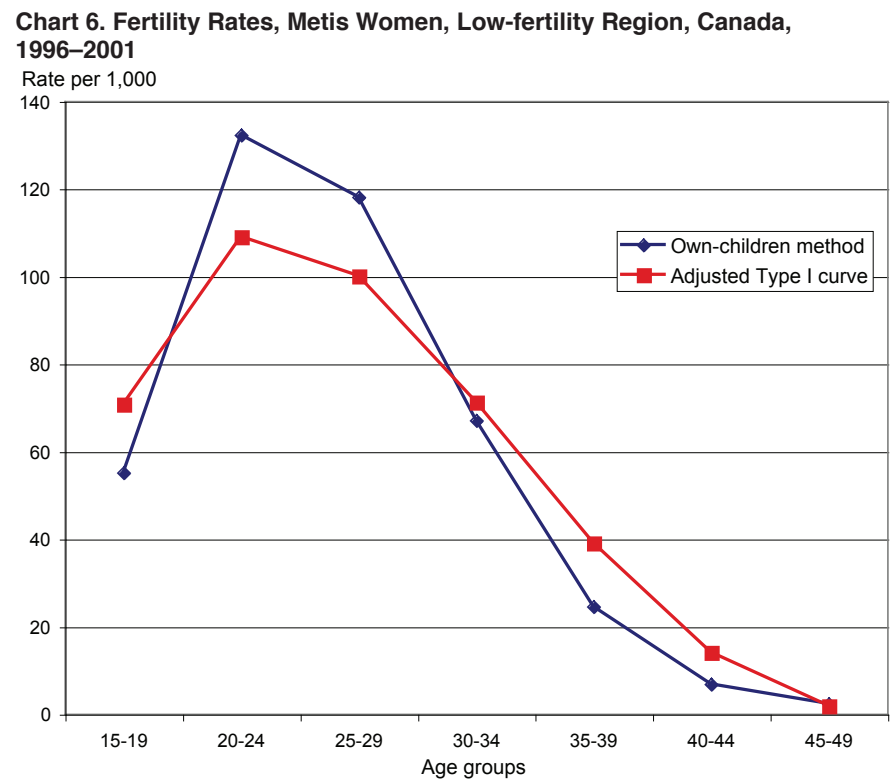

Chart 7. Fertility Rates, Inuit Women, Canada, 1996-2001

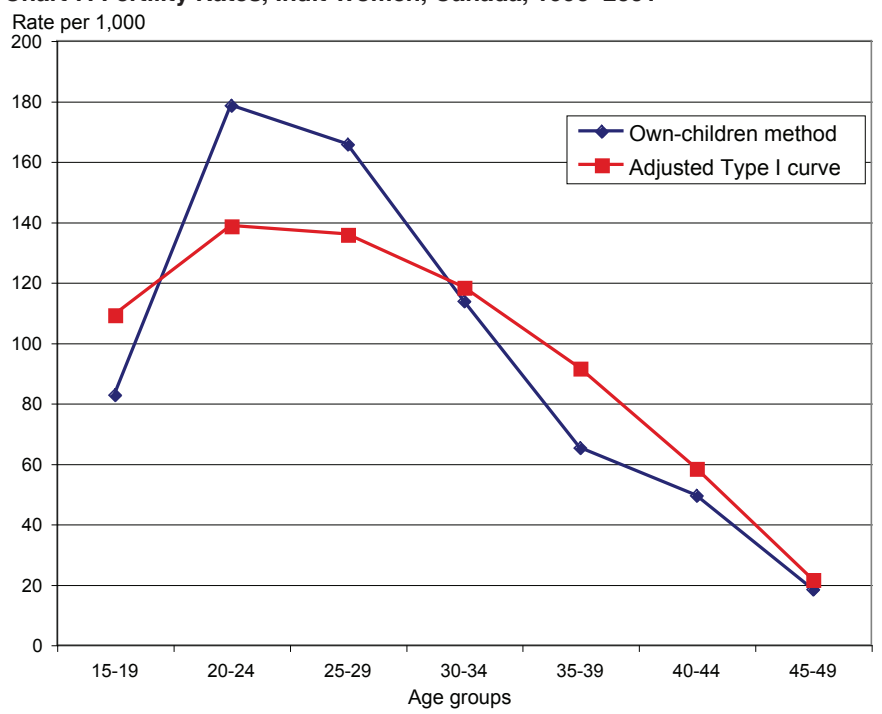

those obtained from the "own-children method." Under age 30, the Type I based agespecific fertility rates are lower than those estimated by the "own-children method." Over age 30, these curves are higher. This pattern is true for all three Aboriginal identity groups. Are these differences between the two sets of age-specific fertil- 
ity rates statistically significant? For this, we tested their differences using the Chisquare test, and we observed that the differences between the two sets of age-specific fertility rates for each Aboriginal group were not statistically significant (see Table 2). Consequently, in Table 3 it was observed that the number of births estimated by these two methods differed very little due to minor differences in the estimated agespecific fertility rates only; since we have used the same age distribution of women aged 15-49 years in estimating the number of births by these two methods.

\section{Concluding Remarks}

The values of the three parameters of fertility distribution $\left(\varkappa, \beta_{1}\right.$, and $\beta_{2}$ criteria) support that regardless of fertility region, the Type I curve is an appropriate curve for graduating age-specific fertility rates for each Aboriginal identity group in Canada. The ratios of the number of births generated from the model (Type I curve) and the estimated number of births based on the "own-children method" are found to deviate very little from $100 \%$. The relative differences in the number of births estimated by the two methods range from $-0.50 \%$ for Métis in high-fertility region to $1.42 \%$ for Métis in the low-fertility region.

Are the births using the Type I curve for the Aboriginal identity groups in Canada projected precisely? Our evaluation of the Type I curve demonstrated that the births based on the Type I curve were generally overestimated as compared to those based on the "own-children method," but the differences between these methods were very small and statistically insignificant. Thus, the test of validity and the three parameters of the fertility distribution based on the period 1996-2001 provide support for the use of the Type I curve to project the births of the Aboriginal populations from 2001-2017. The experience of the national population projections precludes the sole use of the Type I curve without considering the changes in the level and age structure of fertility. Other Types of curve in the Pearson system of frequency curves should be examined when the fertility data are based on other time periods.

\section{Acknowledgements}

This is a revised version of the paper presented at the poster session of the 2006 annual meetings of the Population Association of America, Los Angeles, California. The authors appreciate the useful suggestions from Réjean Lachapelle and Bali Ram, Statistics Canada and two anonymous reviewers of this journal. We also thank Julie Dussault and Marta Kanigan for providing technical assistance and Ian Kisbee for editorial assistance. The views expressed in this paper are those of the authors and do not necessarily reflect those of Statistics Canada. 


\section{Appendix I Estimation of Total Fertility Rates by the Own-children Method}

The "own-children method" (Cho, Grabill, and Bogue, 1970; Grabill and Cho, 1965) is an appropriate method for estimating total fertility rates for women of the three Aboriginal groups, since it uses census data on the enumerated number of children classified by age and age of mothers. Total fertility rates for the three Aboriginal groups for the period 1996-2001 were estimated by reverse surviving the number of young children under the age of " $x$ " years (under the age of 5 in this case) and women in reproductive age groups reported in the 2001 Census. This method is based on the assumption that children under the age of 5 years at the time of the census represent the survivors of all children born during the five years preceding the census. By estimating age-specific fertility rates using this indirect method, the two parameters on the age pattern of fertility, which are required by the model, could also be derived.

Due to the small number of certain Aboriginal populations in some provinces and territories, it was deemed appropriate to group the provincial data into two regions: a high-fertility region and a low-fertility region. The grouping of the provinces and territories was based on the level of fertility for Aboriginal peoples in Canada, the provinces and territories, in 1991-1996 and 1996-2001 estimated by Ram (2003). During both periods, the total fertility rates of Aboriginal peoples in Manitoba, Saskatchewan, Yukon Territory, Northwest Territories, and Nunavut were higher than the national average; thus, these provinces were combined as the high fertility region. Conversely, the low-fertility region consisted of Newfoundland and Labrador, Prince Edward Island, Nova Scotia, New Brunswick, Quebec, Ontario, Alberta and British Columbia.

The estimation of total fertility rates using the "own-children method" involved the following steps. First, data were retrieved from the 2001 Census on the number of children aged 0-4 years in families, by age of mother, Aboriginal group, provinces, territories, and Canada. Women aged 15-19 to 50-54 were also retrieved from the 2001 Census. For North American Indians and the Métis, data for the high-fertility region were obtained by summing the number of children and women in Manitoba, Saskatchewan, Yukon Territory, Northwest Territories, and Nunavut. The number of children and women in the low-fertility region was obtained by summing the appropriate data of Newfoundland and Labrador, Prince Edward Island, Nova Scotia, New Brunswick, Quebec, Ontario, Alberta, and British Columbia. Second, the distribution of all children by age of women, including those away from their mothers, was constructed by prorating the total population aged $0-4$ in the census. This was done to compensate for those children who were put up for adoption or were being raised by lone-parent males or by other relatives. Third, appropriate survival ratios were applied to the number of children aged 0-4 in the census, in order to translate the number of children into births (numerator) 0-4 years preceding the census. By account- 
ing for the number of children who had died, this procedure provided an estimate of the number of children who might have been born during the 5 year period preceding the census. Fourth, the number of women was reverse survived, using the appropriate survival ratios. The average of the population at the census and the reverse survived population 5 years ago provided the mid-year population of women (denominator). Fifth, dividing the estimated number of births by the mid-year population of women produced the cumulative fertility of five years. Sixth, average annual age-specific fertility rates were derived for the five years preceding the 2001 Census, by applying Grabill and Cho's (1965) "Sprague fifth difference osculatory interpolation" multipliers to these cumulative rates. Seventh, total fertility rates by Aboriginal group and region were obtained by summing the respective age-specific fertility rates.

\section{References}

Cho, L.J. 1973. The Own-children Approach to Fertility Estimation: An Elaboration. International Union for the Scientific Study of Population, International Population Conference, Liege, Volume 2:263278.

1971. On Estimating Annual Birth Rates from Census Data on Children. Proceedings of the Social Statistics Section, American Statistical Association.

Cho, L.J., W.H. Grabill and D.J. Bogue. 1970. Differential Current Fertility in the United States. Chicago: University of Chicago Press.

Elderton, W.P. 1930. Frequency Curves and Correlation. Cambridge: Cambridge University Press.

Grabill, W.H. and L.J. Cho. 1965. "Methodology for the measurement of current fertility from population data on young children." Demography 2:50-73.

Guimond, E. 1999. Ethnic mobility and demographic growth of Canada's Aboriginal populations from 1986 to 1996. Report on the Demographic Situation in Canada 1998-1999. Catalogue no. 91-209-X. Ottawa: Statistics Canada.

Loh, S. 1997. Progress Report on Estimating Total Fertility Rates for Registered Indians, 1974-1996 and Projecting the Rates to 2021. Report prepared by the Population Projections Section, Demography Division, Statistics Canada for the Department of Indians Affairs and Northern Development.

Mitra, S. 1992. Some Observations on Modelling Fertility Rates. Report submitted to Demography Division, Statistics Canada, Ottawa.

Ram, B. 2004. "New estimates of Aboriginal fertility, 1966-1971 to 1996-2001." Canadian Studies in Population, 31(2):179-196.

2003. Emerging Patterns of Aboriginal Fertility, 1966-1971 to 1996-2001. Paper presented at the annual meeting of the Canadian Population Society, Halifax, Nova Scotia, May.

1991. Assimilation and Fertility of Native Indians: Some New Evidence. Paper presented at the annual meeting of the Canadian Population Society, Kingston, Ontario, June.

Ram, B. and A. Romaniuc. 1985. Fertility Projections of Registered Indians, 1982 to 1996. Indian and Northern Affairs Canada. Ottawa.

Romaniuc, A. 1975. "A Three Parameter Model for Birth Projections" Pp. 39-54 in Technical Report on Population Projections for Canada and the Provinces 1972-2001, Ottawa: Statistics Canada, 
Catalogue No. 91-516 Occasional.

Siggner, A. and J. Hagey. 2004. Measuring demographic and non-demographic change in the Aboriginal population residing in urban areas of Canada. Paper presented at the annual meetings of the Canadian Population Society, Manitoba, June 2004.

Statistics Canada. 2005. Projections of the Aboriginal Populations, Canada, Provinces and Territories, 2001 to 2017. Catalogue no. 91-547-XIE. Ottawa.

- Description of Population Projections of Registered Indians for Canada and Regions, 2000-2021. Demography Division, submitted to the Department of Indian Affairs and Northern Development, pp.1-18. Ottawa.

2001. Population Projections for Canada, Provinces and Territories 2000-2026. Catalogue no. 91-520 Occasional. Ottawa.

1994. Population Projections for Canada, Provinces and Territories 1993-2016, Catalogue no. 91-520 Occasional. Ottawa.

1975. Technical Report on Population Projections for Canada and the Provinces 1972-2001, Catalogue No. 91-516 Occasional, Ottawa.

Stuart, A. and J.K. Ord. 1987. Kendall's Advanced Theory of Statistics, originally by Sir Maurice Kendall, Vol. 1, Distribution Theory. New York: Oxford University Press.

Verma, R.B.P. 2005. Evaluation of Projections of Populations for the Aboriginal Identity Groups in Canada, 1996-2001. Canadian Studies in Population 32(2):229-255.

Verma, R.B.P., S. Loh, S.Y. Dai, and D. Ford. 1996. Fertility Projections for Canada, Provinces and Territories, 1993-2016. Statistics Canada, Catalogue no. 91F001MIE, Ottawa.

Verma, R.B.P. and D. Ford. 1992. Fertility Rates by Age of Mothers: Pearson Curve Type I vs. Types II, III and Normal. Paper prepared for presentation at the Federal Provincial Committee on Demography meeting, Statistics Canada, Ottawa. December 1-2.

Verma, R.B.P. and S. Loh. 1992. Evaluation of Pearsonian Type I Curve of Fertility by Age of Mother for Canada, Provinces and Territories, 1980-1989. Paper presented at the Canadian Population Society meeting, Charlottetown, P.E.I., June 2-5. 